\title{
Obtaining First and Second Order Nomoto Models of a Fluvial Support Patrol using Identification Techniques
}

DOI: 1 https://doi.org/10.25043/19098642.160

Sandra Carrillo ${ }^{1}$

Juan Contreras ${ }^{2}$

\begin{abstract}
In this paper we present a method for obtaining a second order Nomoto model that describes the yaw dynamic of a Patrol River Boat. This model is obtained from experimental input and output data gathered from the turning circle maneuver. System identifications techniques and a gray box model are employed to find the coefficients of the Nomoto model. The results of the identification process as well as the results of validation process are presented.
\end{abstract}

Key words: second order Nomoto model, coefficients of Nomoto, maneuverability, system identification, gray box model.

\section{Resumen}

Este artículo describe la obtención del modelo de Nomoto de segundo orden para una patrullera de apoyo fluvial PAF a partir de datos experimentales, derivados de pruebas estándares de maniobra realizadas en aguas poco profundas. Se utilizan técncias de identificación de sistemas y un modelo de caja gris que permite extraer los coeficientes del modelo de Nomoto. Se presentan los resultados del proceso de identificación, así como de los procesos de validación utilizando datos de pruebas diferentes a la empleada en la identificación.

Palabras claves: modelo de Nomoto de segundo orden, coeficientes de Nomoto, mabiobrabilidad, identificación de sistemas, modelo de caja gris.

Date Received: July $1^{\text {st }} 2017$ - Fecha de recepción: Julio 1 de 2017

Date Accepted: November 23 2017 - Fecha de aceptación: Noviembre 23 de 2017

\footnotetext{
${ }^{1}$ Escuela Naval de Cadetes Almirante Padilla, Cartagena, Colombia. Email: spcarrillo@gmail.com

${ }^{2}$ Escuela Naval de Cadetes Almirante Padilla, Cartagena, Colombia. Email: epcontrerasj@ieee.org
} 


\section{Introduction}

According to the International Maritime Organization, IMO, the International Association of IMCA Marine Contractors, and other classes of certification societies, a dynamic positioning vessel is related to the automatic control of the position of the vessel and the course with respect to one or more position references for the use of active propellers [1]. Maintaining the course of a vessel is a complex problem due to the vessel's nonlinear dynamics, but it has a great impact on the economy, safety and operation of vessels $[2,3]$.

For the description of the dynamics of surface vehicles, the authors have used different types of models, such as the Nomoto model $[4,5,6]$, the Norbin model [7] and others.

For the data of the tests the Patrol Boat of Heavy Fluvial Support "PAF-P" of 3rd generation built by COTECMAR 2009 has been taken as a study model. The ship was subjected to the approval of an evolutionary circle at different approach speeds and rudder angles. , zig-zag and emergency stop in shallow water $(\mathrm{H} / \mathrm{T}=2.4)$ and deep water $(\mathrm{H} /$ $\mathrm{T}>10)[8,9]$.

\section{Linear Maneuver Model}

\section{Equations of rigid body dynamics}

The equations that control the dynamics of a ship are derived from the equations of motion of a rigid body with 6 degrees of freedom. These equations are shown below in vector form [10]:

$M_{R B} \dot{v}+C_{R B}(\dot{v}) v=\tau_{R B}$

Where $M_{R B}$ is the mass matrix, $C_{R B}$ is the centripetal and coriolis matrix, $v$ is the angular and linear velocity vector of the rigid body $\left([u, v, w, p, q, r]^{T}\right)$ and $\tau_{R B}$ is the generalized vector of external forces and moments $\left([X, Y, Z, K, M, N]^{T}\right)$.

From equation (1) an expansion of the terms of the 6 degrees of freedom is made [10]:

$$
\begin{aligned}
& m|\dot{u} \quad v r| w q \quad x_{G}\left(q^{2} \mid r^{2}\right)\left|y_{G}(p q \dot{r})\right| z_{G}(p r \mid \dot{q}) \mid X \\
& m|\dot{v} \quad w p| u r \quad y_{G}\left(r^{2} \mid p^{2}\right)\left|z_{G}(q r \dot{p})\right| x_{G}(q p \mid \dot{r}) \mid \quad Y \\
& m|\dot{w} \quad u q| v p \quad z_{G}\left(p^{2} \mid q^{2}\right)\left|x_{G}\left(\begin{array}{ll}
r p & \dot{q}
\end{array}\right)\right| y_{G}(r q \mid \dot{p}) \mid Z
\end{aligned}
$$

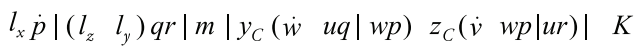

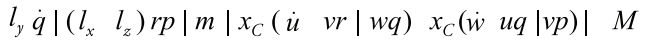

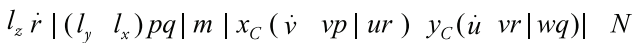

Where $X, Y, Z$ are external and hydrodynamic disturbing forces and $K, M$ and $N$ are hydrodynamic and external disturbance moments.

To simplify this model of equations of six degrees of freedom to 3 degrees, the following assumptions are made:

1. The ship is symmetric around the $x-z$ plane $\left(I_{x y}=I_{y z}=y_{G}=0\right)$.

2. The vessel has a homogeneous mass distribution.

3. The fixed origin of the body is selected as

$$
r_{G}=\left[\begin{array}{lll}
x_{G} & 0 & z_{G}
\end{array}\right]^{T}(1 x z=0)
$$

4. The tipping, tilt and roll are ignored

$$
(q=w=p=0) \text {. }
$$

This produces three simplified nonlinear equations:

$$
\begin{array}{ll}
\text { surge: } & m\left(\dot{u}-v r-x_{G} r^{2}\right)=X \\
\text { sway: } & m\left(\dot{u}+u r+x_{G} \dot{r}\right)=Y \\
\text { yaw: } & l_{z} \dot{r} \mid m x_{G}(\dot{v} \mid u r) \quad N
\end{array}
$$

The disturbed equations of motion are based on an additional assumption:

- The speed of deviation (sway) $v$, and the yaw rate $r$ and the rudder angle $\delta$ are small.

This implies that the mode of advance (surge) can be dissociated from the yaw and deflection modes assuming that the average speed of advance $u_{0}$ is constant for a constant thrust. In the same way, it is assumed that the average yaw and yaw velocities are $v_{0}=r_{0}=0$. As such:

$$
\begin{array}{lll}
u=u_{0}+\Delta u ; & v=\Delta v ; & r=\Delta r \\
X=X_{0}+\Delta X ; & Y=\Delta Y ; & V=\Delta V
\end{array}
$$

Where $\Delta u, \Delta v$ and $\Delta r$ are small disturbances of nominal values $u_{0}, v_{0}$ and $r_{0}$, and $\Delta X, \Delta Y$ and $\Delta Z$ 
are small disturbances of nominal values $X_{0}, Y_{0}$ and $N_{0}$.

Assuming that higher order disturbances can be neglected, the nonlinear equations of motion can be expressed as:

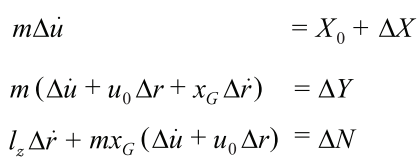

Note that the governing equations of motion are completely decoupled from the velocity equation.

$$
\begin{array}{ll}
\text { velocity equation: } & m \Delta \dot{u} \quad=X \\
\text { gobernance equation: } & m\left(\dot{u}+u_{0} r+x_{G} \dot{r}\right)=Y \\
& l_{z} \dot{r}+m x_{G}\left(\dot{u}+u_{0} r\right)=N
\end{array}
$$

The assumption that the average forward speed is constant implies that this model is only valid for small rudder angles.

\section{First-order Nomoto equation}

Starting from the governance equation:

$l_{z} \dot{r}+m x_{G}\left(\dot{u}+u_{0} r\right)=N$

Reorganizing and replacing the governance time constant $T=l z / m x_{G} u_{0}$ and the rudder gain $K=$ $N / \delta_{R} m x_{G} u_{0}$ would be expressed as the First Order Nomoto Equation of the form [11]:

$T \dot{r}+r=K \delta_{R}$

Or alternatively:

$\operatorname{Tr} \dot{\psi}+\dot{\psi}=K \delta_{R} \quad$ con $\dot{\psi}=r$

Reorganized the equation to the state-space form $x$ $=A x+B u y \quad y=C x$, The First Order Nomoto model becomes:

$$
\begin{aligned}
& {\left[\begin{array}{l}
\dot{\psi} \\
r
\end{array}\right]=\left[\begin{array}{cc}
0 & 1 \\
0 & -\frac{1}{T}
\end{array}\right]\left[\begin{array}{l}
\psi \\
r
\end{array}\right]+\left[\begin{array}{l}
0 \\
\frac{K}{T}
\end{array}\right] \delta_{R} \quad \text { (Constant Time form) }} \\
& {\left[\begin{array}{l}
\dot{\psi} \\
r
\end{array}\right]=\left[\begin{array}{ll}
0 & 1 \\
0 & a_{22}
\end{array}\right]\left[\begin{array}{l}
\psi \\
r
\end{array}\right]+\left[\begin{array}{l}
0 \\
b_{2}
\end{array}\right] \delta_{R} \quad \text { (Parametric form) }}
\end{aligned}
$$

\section{Second order Nomoto equation}

A second-order deviation-yaw model is obtained from the motion equations with 3 degrees of freedom and uncoupled in advance, assuming small perturbations we have:

\section{Governance equiations}

$m\left(\dot{u}+u_{0} r+x_{G} \dot{r}\right)=Y$

$l_{z} \dot{r}+m x_{G}\left(\dot{u}+u_{0} r\right)=N$

Assuming the origin in the center of gravity $\left(x_{G}=\right.$ 0 ). The linear theory suggests that hydrodynamic force and momentum can be modeled as (Davidson and Schiff, 1946) [12]:

$$
\begin{aligned}
& Y=Y_{\dot{v}} \dot{v}+Y_{\dot{r}} \dot{r}+Y_{v} v+Y_{r} r+Y_{\delta} \delta_{R} \\
& N=N_{\dot{v}} \dot{v}+N_{\dot{r}} \dot{r}+N_{v} v+N_{r} r+N_{\delta} \delta_{R}
\end{aligned}
$$

Therefore, we can write the equations of motion in the form of state-space according to:

$M \dot{v}+N\left(u_{0}\right) \dot{v}=b \delta_{R}$

and the Nomoto model is obtained:

Where $v=[v, r]^{T}$ is the state vector, $\delta_{R}$ the rudder angle, and:

$M=\left[\begin{array}{lr}m-Y_{\dot{v}} & m x_{G}-Y_{\dot{r}} \\ m x_{G}-N_{\dot{v}} & l_{z}-N_{\dot{r}}\end{array}\right] ; \quad N_{\left(u_{0}\right)}=\left[\begin{array}{rr}-Y_{v} & m u_{0}-Y_{r} \\ -N_{v} & m x_{G} u_{0}-N_{r}\end{array}\right] ;$

$b=\left[\begin{array}{l}Y_{\delta} \\ N_{\delta}\end{array}\right]$

The $N\left(u_{0}\right)$ matrix is obtained by the is obtained by the linear sum of the damping $D$ and the terms of Coriolis $C\left(u_{0}\right)$ and centripetal (additional terms $m u_{0}$ and $\left.m x_{G} u_{0}\right)$, which means:

$N_{\left(u_{0}\right)}=C_{\left(u_{0}\right)}+D$

The corresponding space-state model is obtained, leaving $v=[v, r]^{T}$ is the state vector and $u=\delta_{R}$.

As such:

$\dot{x}=A x+b_{1} u$ 
with:

$A=-M^{-1} N=\left[\begin{array}{ll}a_{11} & a_{12} \\ a_{21} & a_{22}\end{array}\right] ; \quad b_{1}=-M^{-1} b\left[\begin{array}{l}b_{1} \\ b_{2}\end{array}\right]$

The coefficients are defined as [13]:

$a_{11}=\frac{\left(l_{z}-N_{\dot{r}}\right) Y_{v}-\left(m x_{G}-Y_{\dot{r}}\right) N_{v}}{\operatorname{det}(M)}$

$a_{12}=\frac{\left(l_{z}-N_{\dot{r}}\right)\left(Y_{r}-m u_{0}\right)-\left(m x_{G}-Y_{\dot{r}}\right)\left(N_{\dot{r}}-m x_{G} u_{0}\right)}{\operatorname{det}(M)}$

$a_{21}=\frac{\left(m-Y_{i}\right) N_{v}-\left(m x_{G}-N_{i}\right) Y_{v}}{\operatorname{det}(M)}$

$a_{22}=\frac{\left(m-Y_{\dot{v}}\right)\left(N_{r}-m x_{G} u_{0}\right)-\left(m x_{G}-N_{\dot{v}}\right)\left(Y_{\dot{r}}-m u_{0}\right)}{\operatorname{det}(M)}$

$b_{1}=\frac{\left(l_{z}-N_{\dot{r}}\right) Y_{\delta}-\left(m x_{G}-Y_{\dot{r}}\right) N_{\delta}}{\operatorname{det}(M)}$

$b_{2}=\frac{\left(m-Y_{\dot{v}}\right) N_{\delta}-\left(m x_{G}-N_{\dot{i}}\right) Y_{\delta}}{\operatorname{det}(M)}$

These models are obtained by eliminating the deviation speed from $M \dot{v}+N\left(u_{0}\right) \dot{v}=b \delta_{R}$ to get the Nomoto transfer function between $r$ and $\delta_{R}$, which is:

$\frac{r}{\delta_{R}}(s)=\frac{K_{R}\left(1+T_{3} s\right)}{(1+s)\left(1+T_{2} s\right)}$

The parameters of the transfer function are the relationships with hydrodynamic derivatives such as:

$$
\begin{aligned}
& T_{1} T_{2}=\frac{\operatorname{det}(M)}{\operatorname{det}(N)} \\
& T_{1}+T_{2}=\frac{n_{11} m_{22}+n_{22} m_{11}-n_{12} m_{21}-n_{21} m_{12}}{\operatorname{det}(N)} \\
& K_{R}=\frac{n_{21} b_{1}-n_{11} b_{2}}{\operatorname{det}(N)} \\
& K_{R} T_{3}=\frac{m_{21} b_{1}-m_{11} b_{2}}{\operatorname{det}(N)}
\end{aligned}
$$

Where the elements $n_{i j}, m_{i j}$ and $b_{i}$ are defined as:

$$
\begin{aligned}
M & =\left[\begin{array}{lr}
m-Y_{\dot{v}} & m x_{G}-Y_{\dot{r}} \\
m x_{G}-N_{\dot{v}} & l_{z}-N_{\dot{r}}
\end{array}\right] ; \quad N_{\left(u_{0}\right)}=\left[\begin{array}{rr}
-Y_{v} & m u_{0}-Y_{r} \\
-N_{v} & m x_{G} u_{0}-N_{r}
\end{array}\right] ; \\
b & =\left[\begin{array}{c}
Y_{\delta} \\
N_{\delta}
\end{array}\right]
\end{aligned}
$$

$M=\left[\begin{array}{ll}m_{11} & m_{12} \\ m_{21} & m_{22}\end{array}\right] ; \quad N_{\left(u_{0}\right)}=\left[\begin{array}{ll}n_{11} & n_{12} \\ n_{21} & n_{22}\end{array}\right] ; \quad b=\left[\begin{array}{l}b_{1} \\ b_{2}\end{array}\right]$

Expressing the equation $\dot{x}=A x+b_{1} u$, it becomes state form - space

$$
\left[\begin{array}{c}
\dot{r} \\
\ddot{r}
\end{array}\right]=\left[\begin{array}{cc}
1 & 0 \\
1 & -\frac{T_{1}+T_{2}}{T_{1} T_{2}}
\end{array}\right]\left[\begin{array}{l}
\dot{r} \\
\ddot{r}
\end{array}\right]+\left[\begin{array}{cc}
0 & 0 \\
K_{R} & K_{R} T_{3}
\end{array}\right]\left[\begin{array}{c}
\delta_{R} \\
\dot{\delta}_{R}
\end{array}\right] \delta_{R}
$$

\section{Identification of Mathematical Models}

To obtain a simplified mathematical model (under order) that represents the dynamics in an approximate way, identification techniques were used. In the process of identification and validation of the model that describes the dynamics of the vehicle under study in the horizontal plane, several tests were performed based on the maneuver test of the evolutionary circle. Two (2) of these tests can be seen in Fig. 1 The rudder angle is considered as input and the heading angle as an output.

\section{Obtaining the first order Nomoto model}

It was used, as a second identification technique, the use of the method of least squares using as input the rudder angle and as output the variation of the angle of course (yaw rate), in order to achieve a gray box model that would allow to associate the parameters with the coefficients or indices of a first order Nomoto model. The obtained coefficients are: $\mathrm{K}=-0.0032$ and $\mathrm{T}=0.4702$, with which the first-order Nomoto model is expressed by

$G(s)=\frac{\psi(s)}{\delta(s)}=\frac{K}{s(T s+1)}=\frac{-0.0032}{s(0.4702 s+1)}$

Fig. 2 shows the output, or heading angle, generated by the first-order Nomoto model compared to the actual heading angle. The standardized mean squared error was 0.2883 . 
Fig. 1. Evolution circle maneuver tests used for identification and validation
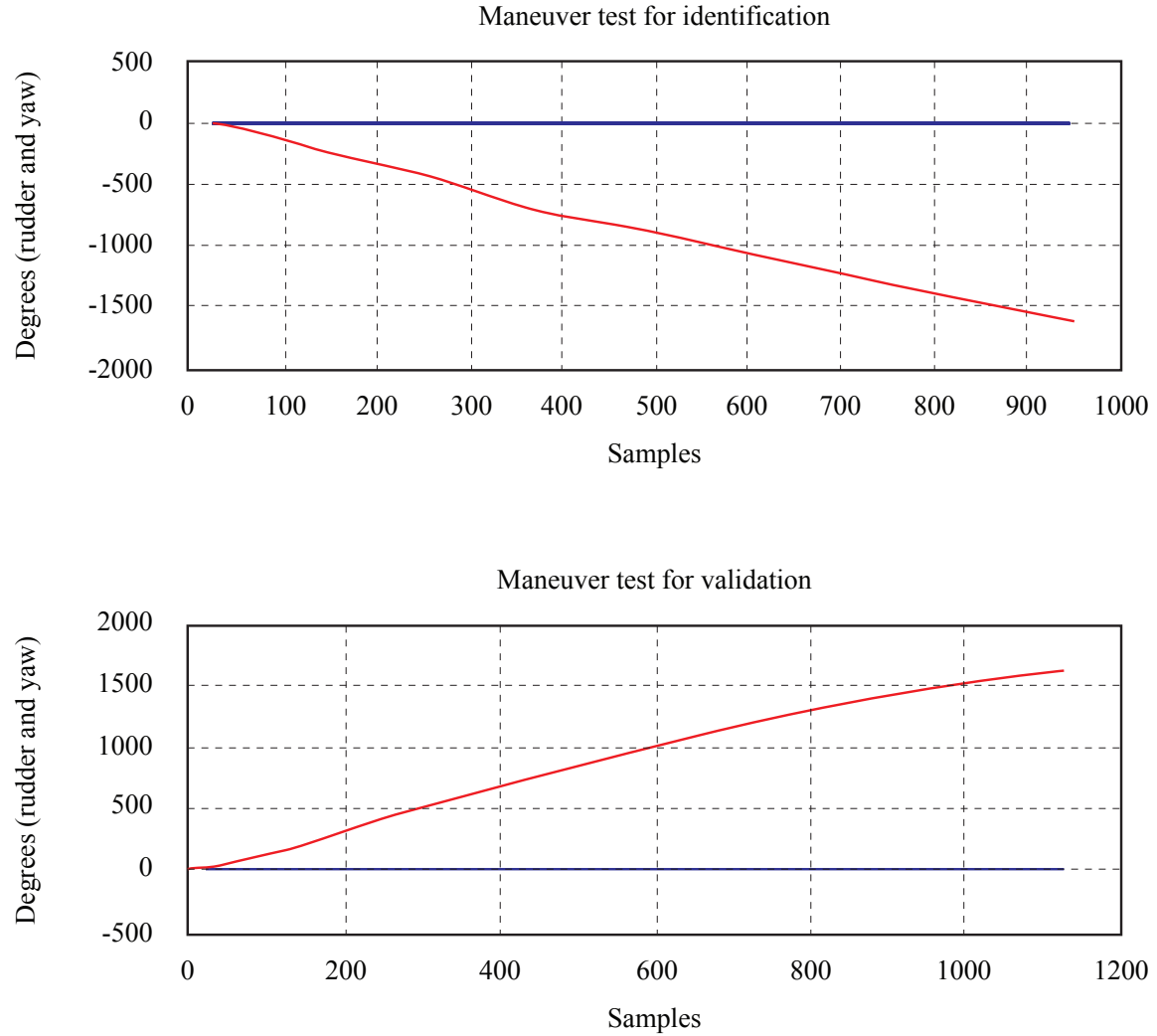

Fig. 2. Comparison between the output of the first order (discontinuous) Nomoto model and the true heading angle

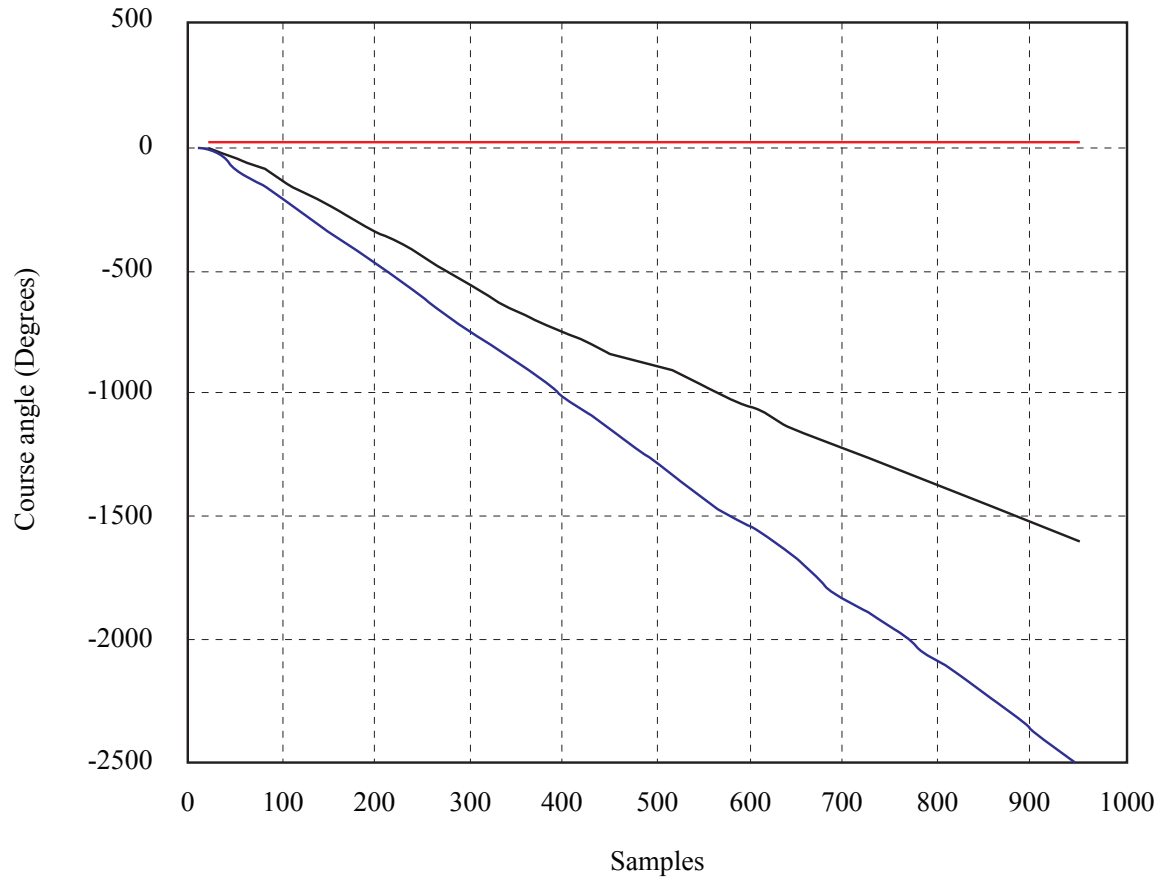


Obtaining second order Nomoto model $\quad b_{0}=A_{1}+A_{2}$

The second-order Nomoto model is given by the $b_{1}=\left(A_{1}\left(e^{-\frac{1}{T_{2}} T}\right)+A_{2}\left(e^{-\frac{1}{T_{1}} T}\right)\right)$ expression:

$G(s)=\frac{\psi(s)}{\delta(s)}=\frac{K\left(T_{3} s+1\right)}{\left(T_{1} s+1\right)\left(T_{2} s+1\right)}=\frac{\frac{K T_{3}}{T_{1} T_{2}}\left(s+\frac{1}{T_{3}}\right)}{\left(s+\frac{1}{T_{1}}\right)\left(s+\frac{1}{T_{2}}\right)}$

If we break down by partial fractions, we have to

$G(s)=\frac{\psi(s)}{\delta(s)}=\frac{A_{1}}{\left(s+\frac{1}{T_{1}}\right)}+\frac{A_{2}}{\left(s+\frac{1}{T_{2}}\right)}$

With which the following is obtained

$$
A_{1}=\frac{K\left(T_{1}-T_{3}\right)}{T_{1}\left(T_{1}-T_{2}\right)} ; \quad A_{2}=\frac{K\left(T_{2}-T_{3}\right)}{T_{2}\left(T_{2}-T_{1}\right)}
$$

That is, the response in the time domain will be given by

$\psi(t)=\frac{K\left(T_{1}-T_{3}\right)}{T_{1}\left(T_{1}-T_{2}\right)} * e^{-\frac{1}{T_{1}} t}+\frac{K\left(T_{2}-T_{3}\right)}{T_{2}\left(T_{2}-T_{1}\right)} * e^{-\frac{1}{T_{2}} t}$

Then, in the $Z$ domain

$G(z)=A_{1} \frac{1}{1-e^{-\frac{1}{T_{1} T} z^{-1}}}+A_{2} \frac{1}{1-e^{-\frac{1}{T_{2}} T} z^{-1}}$

$G(z)=\frac{A_{1}\left(1-e^{-\frac{1}{T_{2}} T} z^{-1}\right)+A_{2}\left(1-e^{-\frac{1}{T_{2}} T} z^{-1}\right)}{\left(1-e^{-\frac{1}{T_{1}} T} z^{-1}\right)\left(1-e^{-\frac{1}{T_{2}} T} z^{-1}\right)}$

$G(z)=\frac{A_{1}+A_{2}-\left(A_{1}\left(e^{-\frac{1}{T_{2}} T}\right)+A_{2}\left(e^{-\frac{1}{T_{1}} T}\right)\right) z^{-1}}{\left(-1\left(e^{-\frac{1}{T_{1}} T}+e^{-\frac{1}{T_{2}} T}\right) z^{-1}+e^{-\left(\frac{1}{T_{1}}+\frac{1}{T_{2}}\right)} z^{-2}\right)}$

Where $T$ is the sampling time.

If we make an analogy with a discrete second-order model expressed by the following equation:

$G(z)=\frac{b_{0}+b_{1} z^{-1}}{1+a_{1} z^{-1}+a_{2} z^{-2}}$

We have that:
$a_{1}=-\left(e^{-\frac{1}{T_{1}} T}+e^{-\frac{1}{T_{2}} T}\right)$

$a_{2}=e^{-\left(\frac{1}{T_{1}}+\frac{1}{T_{2}}\right) T}$

Where we get:

$$
\begin{aligned}
& \ln \left(a_{2}\right)=\left(\frac{T}{T_{1}}+\frac{T}{T_{2}}\right) \\
& T_{2}=\frac{T}{-\frac{T}{T}-\ln \left(a_{2}\right)}
\end{aligned}
$$

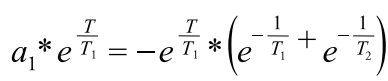

$\left.a_{1} * e^{\frac{T}{T_{1}}}=-e^{\frac{T}{T_{1}}} * e^{-\frac{1}{T_{1}}}-e^{-\frac{1}{T_{2}}} * e^{\left(\frac{T}{T_{1}}+\ln \left(a_{2}\right)\right.}\right)$

$a_{1}{ }^{*} e^{\frac{T}{T_{1}}}=-1-a_{2} * e^{\frac{2 T}{T_{1}}}$

$a_{2}^{*} e^{\frac{2 T}{T_{1}}}+a_{1}^{*} e^{\frac{T}{T_{1}}}+1=0$

$x=e^{\frac{T}{T_{1}}}$

$a_{2} x^{2}+a_{1} x+1=0$

$x_{1,2}=\frac{-a_{1} \pm \sqrt{a_{1}^{2}-4\left(a_{2}\right)(1)}}{2 a_{2}}$

$T_{1}=\frac{T}{\ln \left(x_{1,2}\right)}$

We calculate $K$ it from the gain of the model in discrete time $(z=1)$, as follows:

$K=\frac{\left(b_{0}+b_{1}\right)}{\left(1+a_{1}+a_{2}\right)}$

Finally we find $T_{3}$, as follows:

$b_{0}=A_{1}+A_{2}$ 
$b_{0}=\frac{K\left(T_{1}-T_{3}\right)}{T_{1}\left(T_{1}-T_{2}\right)}+\frac{K\left(T_{2}-T_{3}\right)}{T_{2}\left(T_{2}-T_{1}\right)}$

$b_{0}=\frac{K^{*} T_{3}}{T_{1} T_{2}}$

$T_{3}=\frac{b_{0} T_{1} T_{2}}{K}$

The coefficients obtained are: $K=-0.1724, T_{1}=$ $2.0875, T_{2}=0.3179$ and $T_{3}=0.1830$, with which the second-order Nomoto model is expressed by

$$
\begin{gathered}
G(s)=\frac{\psi(s)}{\delta(s)}=\frac{K\left(T_{3} s+1\right)}{s\left(T_{1} s+1\right)\left(T_{2} s+1\right)}= \\
G(s)=\frac{-0.1724(0.1830 s+1)}{s(2.0875 s+1)(0.3179 s+1)}= \\
\frac{-0.3155 s-0.1724}{0.6636 s^{2}+2.405 s+s}
\end{gathered}
$$

Fig. 3 shows the output, or heading angle, generated by the second-order Nomoto model compared to the actual heading angle. The standardized mean square error obtained was 0.0397 .

Fig. 4 shows the output, or heading angle, generated by the first and second order Nomoto models compared to the actual heading angle in the validation exercise. The standardized mean square error obtained with the first order Nomoto model was 0.3826 , while with the second order Nomoto model it was 0.0516 .

Stability analysis of the second order Nomoto model

Fig. 5 shows the place of the roots of the second order Nomoto model. Three poles are observed: two of them are located on the left side of the plane $S$, which remains on the negative real axis for system gain levels less than 23.6; the other pole is located at the origin and moves to the right if the gain is incremented, which would generate system instability. This pole located in the origin is the one that generates the movement of evolutionary circle for the entrance (change in the rudder) type step.

Fig. 3. Comparison between the output of the second-order (discontinuous) Nomoto model and the actual heading angle with the identification data

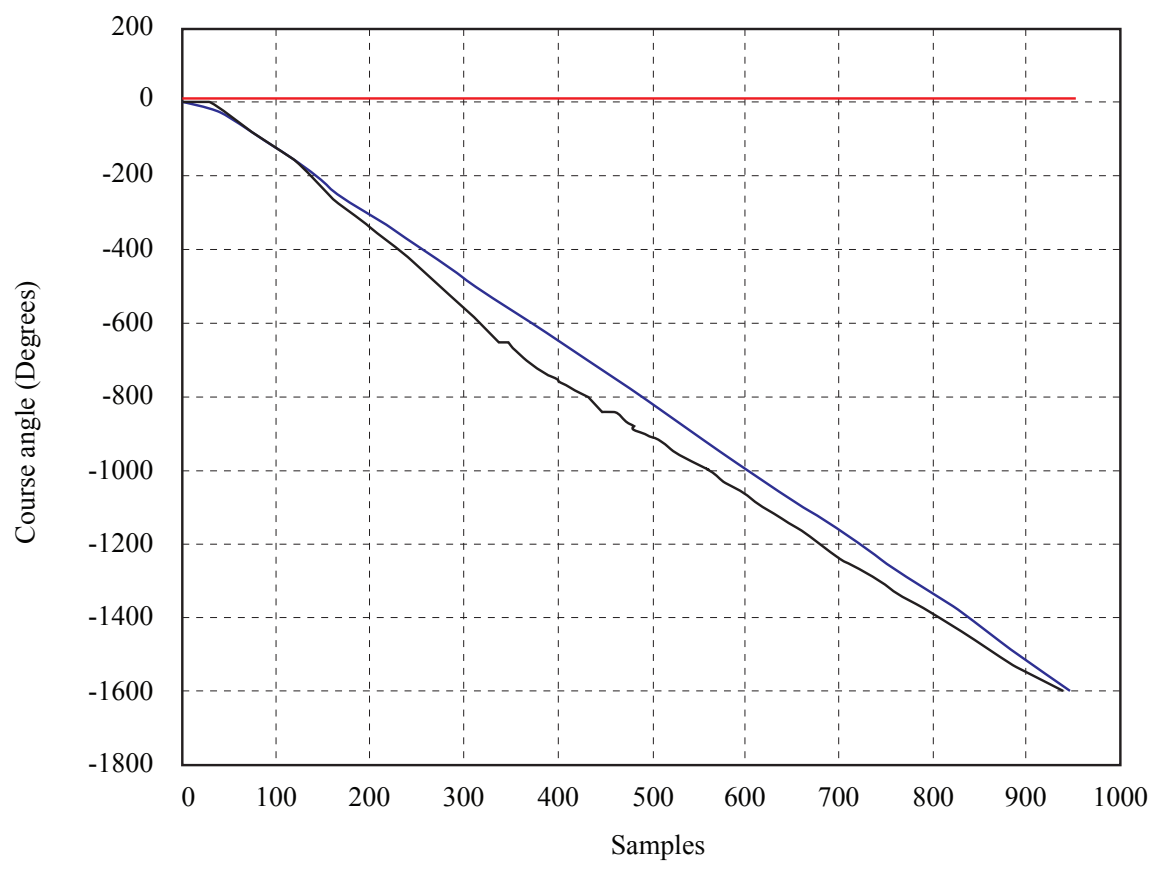


Fig. 4. Comparison between the output of the second-order (discontinuous) Nomoto model and the actual heading angle with the validation data

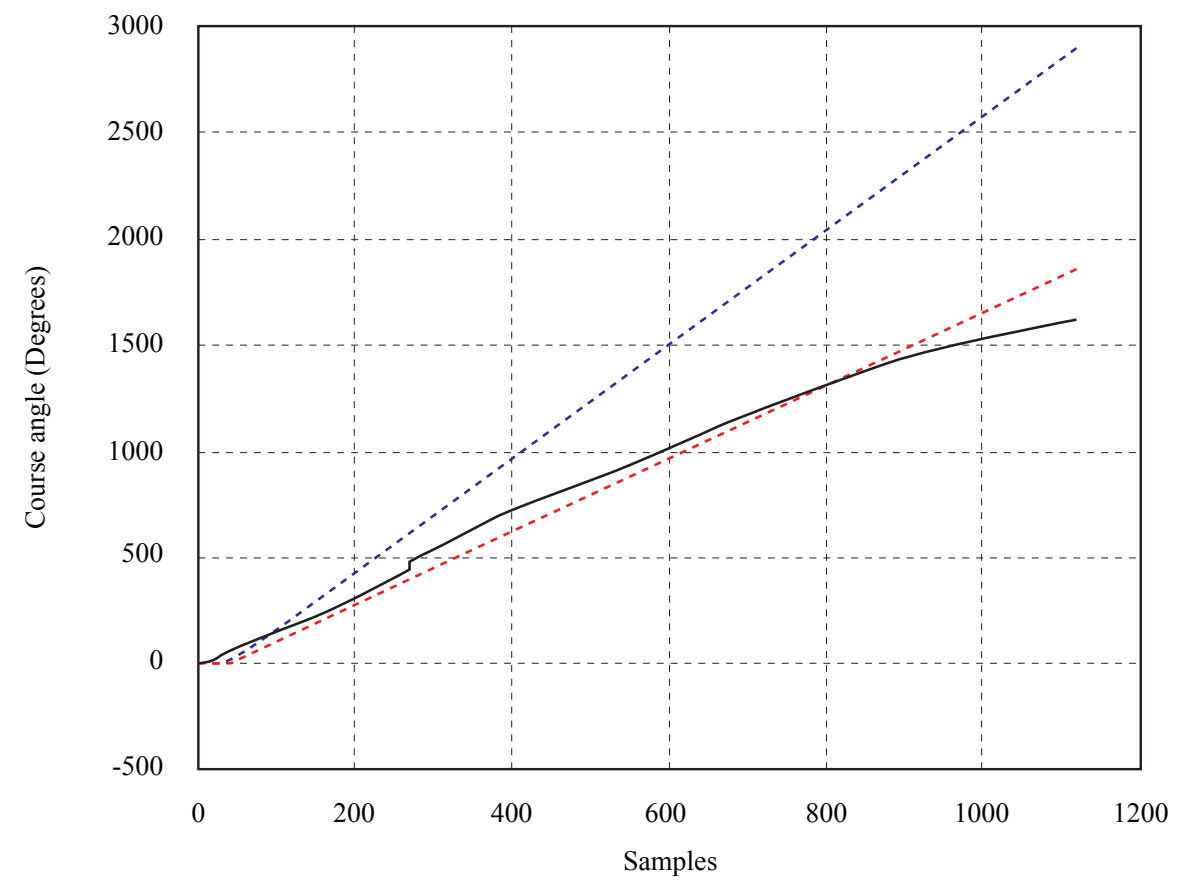

Fig. 5. Place of the roots of the second order Nomoto model

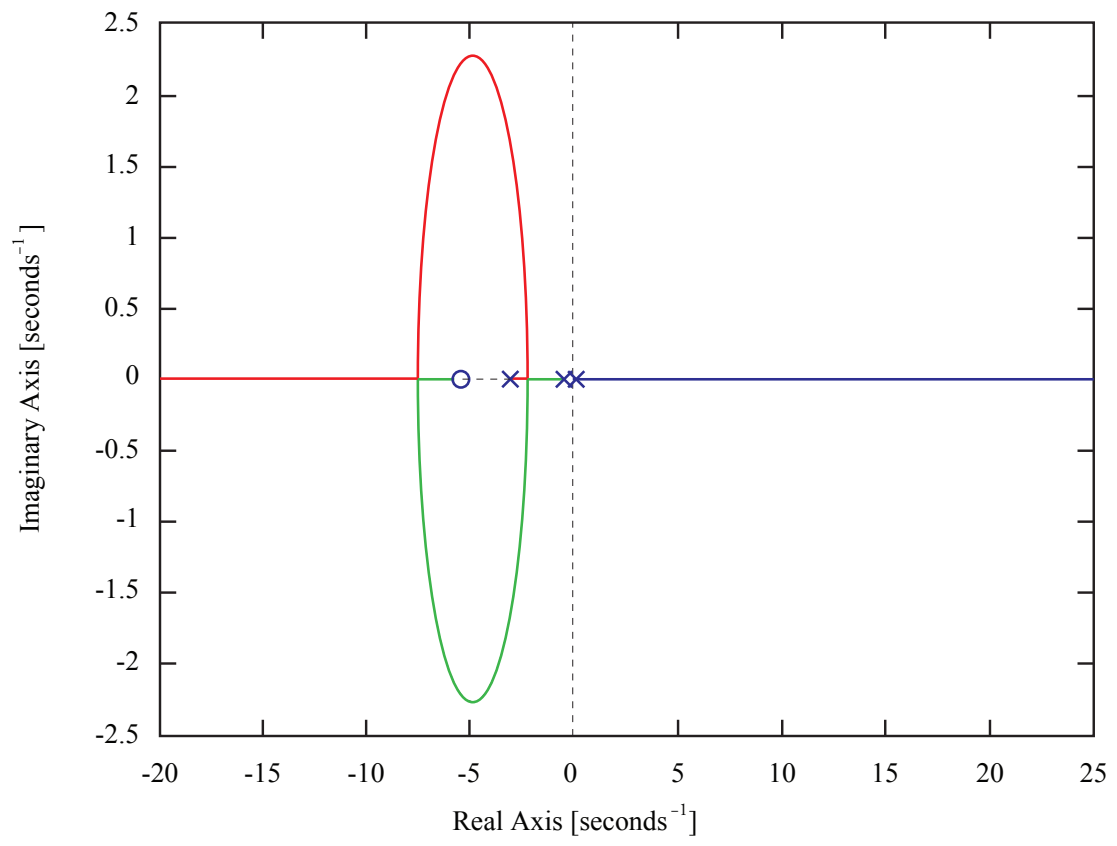

\section{Conclusions}

A methodology was presented to obtain the second order Nomoto model of a PAF fluvial support patrol using identification technique and using experimental data from a standard such as the turning circle maneuver. The mathematical model obtained presents a standardized mean square error 
of 0.0397 in the identification process and 0.0516 in the validation process, which shows a fairly high approximation. The test used for validation was done with a turn to port while the one used for identification was made to starboard.

The analysis of the place of the roots of the Second Order Nomoto model shows the temporal behavior of the system. The pole located at the origin is the one that causes an indefinite turn to port, or starboard, since its location at the origin of the $S$ plane implies an unstable or critically stable behavior.

\section{Acknowledgements}

The authors thank Dr. VALM Jorge Enrique Carreño Moreno, who provided important knowledge to carry out the development of this project.

\section{Bibliography}

[1] WANG MENG, LI HONG SHENG, MIAO QING and BIAN GUANG RONG. "Intelligent control algorithm for ship dynamic positioning". Archives of Control Sciences, Vol. 24, No. 4, p.p.: 479-497. 2014.

[2] HAIJUN XU, WEI LI, YANG YU and YONG LIU. "A Novel Adaptive Neural Control Scheme for Uncertain Ship Coursekeeping System". Sensors \& Transducers, Vol. 178, No. 9, p.p.: 282-285, 2014.

[3] SK. SHARMA, W. NAEEM, R. SUTTON. "An Autopilot Based on a Local Control Network Design for an Unmanned Surface Vehicle". The Journal of Navigation. Vol. 65, p.p.: 281-301. 2012.

[4] VELASCO, F.J., REVESTIDO, E., LÓPEZ, E., MOYANO, E., HARO CASADO, M. "Autopilot and Track-Keeping Simulation of an Autonomous In-scale Fast-ferry Model". 12th WSEAS International Conference on Systems, Heraklion, Greece, July 22-24, 2008.
[5] VELASCO, F.J., REVESTIDO, E., LÓPEZ, E., MOYANO, E., HARO CASADO, M. "Simulation of an Autonomous In-scale Fastferry Model”. International Journal of System Applications, Engineering and Development , Vol. 2, No.3, p.p.: 114-121. 2008.

[6] BANAZADEH A, GHORBANI MT. Frequency domain identification of the Nomotomodel to facilitate Kalman filter estimation and PID heading control of a patrolvessel. Ocean Eng 2013;72:344-55.

[7] AULIA ZITI AISJAH, An Analysis Nomoto Gain and Norbin Parameter on Ship Turning Maneuver, IPTEK, The Journal for Technology and Science, Vol. 21, No. 2, May 2010.

[8] CARREÑO, J. E., "Simulación de maniobras de buques con sistemas de propulsión no convencional en aguas poco profundas", Madrid, España: Universidad Politécnica de Madrid, Tesis doctoral, 2012.

[9] CARREÑO, J. E., MORA, J. D., PÉREZ, F. L., "Mathematical model for maneuverability of a riverine support patrol vessel with a pumpjet propulsion system", Ocean Engineering, Vol. 63, 2013, pp. 96-104

[10 ] T. I. FOSSEN, Guidance and Control of Ocean Vehicles, John Wiley and Sons,New York, 1994.

[11] TZENG, C., and CHEN, J., "Fundamental Properties of Linear Ship Steering Dynamic Models," Journal of Marine Science and Technology, Vol. 7, No. 2, pp 79-88, 1999.

[12] REVESTIDO E., VELASCO F., LÓPEZ E., Diseño de Experimentos para la Estimación de Parámetros de Modelos de Maniobra Lineales de Buques. Elsevier Revista Iberoamericana de Automática e Informática industrial 9 (2012) 123-134. 
[13] POLLAND, S. Recursive parameter identification for estimating and displaying Maneuvering vessel path, Thesis 2003. 